\title{
Patlama Yükleri Etkisi Altında Sismik Yalıtımlı Betonarme Yapıların Performansının İncelenmesi
}

\author{
${ }^{* 1}$ Elif Toplu and ${ }^{2}$ Osman Kirtel \\ ${ }^{* 1}$ Sakarya Uygulamalı Bilimler Üniversitesi, İnşaat Mühendisliği / Teknoloji Fakültesi, Sakarya, Türkiye \\ ${ }^{2}$ Sakarya Uygulamalı Bilimler Üniversitesi, İnşaat Mühendisliği / Teknoloji Fakültesi, Sakarya, Türkiye
}

\section{Özet}

Sismik yalıtım araçları günümüzde yaygın bir şekilde kullanılmaktadır. Özelikle; taban yalıtımında kullanılan kauçuk esaslı sönümleyiciler, ülkemizde 1999 Kocaeli depremi sonrasında oluşan büyük sismik titreşimlerin sönümlenmesi için kullanılmaya başlanmış ve nihayetinde "Türkiye Bina Deprem Yönetmeliği, 2018" de tasarımcılar için bir bölüm olarak eklenmiştir. Ülkemizde yapıların deprem etkilerinin yanı sıra terör faaliyetleri sonucunda patlama etkilerine maruz kaldığı bilinmektedir. Bu çalışmada patlama yükleri etkisi altında yapıların dinamik davranışına sismik yalıtım araçlarının etkisi araştırılmıştır. Çalışma kapsamında mevcut betonarme bir bina modeli oluşturulmuş ve sismik yalıtım aracı olarak kurşun çekirdekli kauçuk sönümleyiciler kullanılmıştır. Mevcut betonarme bir binanın patlama etkileri altında peformansı doğrusal olmayan analiz yöntemlerine göre değerlendirilmiştir.Analiz sonucunda taban yalıtımında kullanılan kurşun çekirdekli kauçuk esaslı sismik sönümleyicilerin patlama yüklerini sönümlemede etkili olduğu görülmüştür.

Anahtar kelimeler: Sismik yalıtım, patlama etkisi, doğrusal olmayan analiz, performans analizi

\begin{abstract}
Seismic isolation tools are widely used today. Especially; elastomeric rubber bearings used in isolation in our country, the 1999 Kocaeli been used for damping of large seismic vibrations that occur after the earthquake, and finally "Turkish Seismic Code 2018" is included as a section for designers. It is known that structures in our country are exposed to blast effects as a result of terrorist activities as well as earthquake effects. In this study, the effect of seismic isolation devices on the dynamic behavior of structures under the influence of blast loads was investigated. Within the scope of the study, an existing reinforced concrete building model was formed and lead rubber bearings were used as seismic isolation tools. The performance of an existing reinforced concrete building under explosion effects was evaluated according to nonlinear analysis methods. As a result of the analysis, it has been seen that lead core rubber based seismic dampers used in base isolation are effective in damping blast loads.
\end{abstract}

Keywords: Seismic isolation, blast effect, nonlinear analysis, performance analysis

"Sorumlu yazar: Adres: Teknoloji Fakültesi, Sakarya Uygulamalı Bilimler Üniversitesi İnşaat Mühendisliği Bölümü, 54187, Sakarya TÜRKIYE. E-mail adresi: eliftoplu@subu.edu.tr, Phone: +902646160767 


\section{Giriş}

Patlama olayları geçmişten günümüze devam eden, yürütülmesi kolay ve hızlı olması bakımından teröristlerin tercih ettiği bir terör faaliyeti olmaktadır. Bombalı saldırı düzenleyen teröristler bir binaya karşı gerçekleştirilecek saldırının etkisini artırabilmek için iki temel faktörü göz önünde bulundurmaktadır: Bunlardan biri kullanılacak patlayıcı maddenin kütlesi, diğeri ise patlamanın gerçekleştirileceği yer ile hedef arasındaki mesafedir. Ancak teröristler saldırılarını optimum hale getirebilmek için hem özgün patlayıcı maddelerini uygun ağırlıkta kullanmaya çalışmakta hem de patlamayı hedef bölgesine en yakın noktada gerçekleştirmek için taşıma yöntemleri geliştirmektedirler. Dolayısıyla saldırı yöntemlerine karşı patlayıcı maddelerin depolandığı, saklandığı, imal edildiği veya taşındığı güzergahlar üzerinde yoğunlaşarak muhtemel patlama noktaları ile hedef bölge arasında fiziki tedbir alınmalıdır [1].

$\mathrm{Bu}$ tür faaliyetlerin gerçekleştirilmesi durumunda, can güvenliğinin sağlanması ve binada oluşabilecek hasarın en aza indirilmesi hedeflenmektedir.Yapılan araştırmalarda deprem sonucunda meydana gelen sismik titreşimlerin sönümlenmesinde etkili olan sönümleyici sistemlerin patlama gibi milisaniyelerde gerçekleşen ani darbe yüklerinin sönümlenmesinde de etkili olabileceğine dair çalışmalar yapılmıştır [2].

Mevcut binalara yönelik patlama kaynaklı terör faaliyetlerinin gerçekleştirilmesi durumunda betonarme binada lokal hasarın meydana gelmesi muhtemeldir.Sismik yalıtım araçları patlama yüklerinin sönümlenmesinde etkili olurken yapının bir bütün halde hareket etmesini sağlayarak yapıda oluşabilecek lokal hasarı azaltabilmektedir.Bu çalışmada sismik yalıtımlı binaların patlama etkileri altında doğrusal olmayan yöntemlerle performans değerlendirmeleri yapılmış ve sismik yalıtım araçlarının hasarı azaltıcı etkisi araştırılmıştır.

\section{Malzeme ve Yöntem}

Çalışma kapsamı; bina modelinin oluşturulması, sismik sönümleyicilerin tasarımı, patlama yüklerinin tasarımı ve zaman tanım alanında doğrusal olmayan analiz ve performans değerlendirmesi şeklindedir.

Mevcut bina modelinde doğrusal olmayan davranış dikkate alınmış, kolon ve kiriş uçlarına plastik mafsal tanımlamaları yapılmıştır.Kolon ve kirişlere "Türkiye Bina Deprem Yönetmeliği, 2018”de tanımlanan çatlamış kesit rijitlikleri oranları atanmıştır.

Taban yalıtımlı binalarda bina periyodu yalıtımsız binalara göre uzun olmaktadır [3] .Yalıtımlı bina periyod değeri 1,5-2,5 saniye arasında alınabilmektedir [4]. Bina hedef periyodu belirlenerek sismik 
yalıtım araçlarının düşeyde kolon normal kuvvetleri, yatayda "Türkiye Bina Deprem Yönetmeliği, 2018"de tanımlanan tasarım depremi dikkate alınarak yük taşıma kapasiteleri belirlenmiştir .

Performans değerlendirmesi "Türkiye Bina Deprem Yönetmeliği, 2018” de tanımlanan birim şekil değiştirme oranlarına göre yapılmıştır. Yapılan analizler sonucunda elde edilen plastik mafsal dönme oranları plastik mafsal boyuna bölünerek eğrilik değerleri elde edilmiştir. XTRACT yazılımı kullanılarak kesit hasar sınırları belirlenmiş ve binaların hasar sınırlarını sağlayıp sağlamadığı konrol edilmiştir.

\section{1. İdeal Patlama}

Patlama dalgası profilinin geliştirilmesi ile ilgili yapılmış birçok araştırma bulunmaktadır(Brode 1955[5]; Henrych 1979[6]; Baker et al.1983[7]; Kingery Bulmash 1984[8]; Kinney ve Grahm 1985[9]).Patlama kaynaklı maksimum basıncı ifade bu yaklaşımlar patlamanın zamana bağlı değişimini ifade eden Friedlander denklemi ile ifade edilmiştir (Denklem 1):

$\mathrm{P}_{\mathrm{s}}(\mathrm{t})=\mathrm{P}_{0}+\mathrm{P}_{\mathrm{so}}\left(1-\frac{t}{t_{o}}\right) \exp \left(-\mathrm{b} \frac{t}{t_{o}}\right)$

Burada $\mathrm{P}_{0}$ : ortam basıncını $[\mathrm{kPa}], \mathrm{P}_{\mathrm{so}}$ : patlama kaynaklı en yüksek basıncı $[\mathrm{kPa}], \mathrm{t}_{\mathrm{o}}$ : basınç dalgası süresini [s] ve b: bozunma katsayısını ifade etmektedir.

\subsection{Eş Değer TNT Ağırlığı ve Ölçeklendirilmiş Mesafe}

Patlayıcı çeşitlerinin fazla olması nedeniyle patlama parametrelerinin hesaplamalarında tek tip bir patlayıcının referans olarak kullanılmasına ihtiyaç duyulmuştur. Bu nedenle TNT'nin eş değer ağırlığı birçok katı tipteki patlayıcıya benzemesinden dolayı referans olarak kullanılmaktadır. Bir patlayıcının eş değer TNT ağırlığı patlama sırasında üretilen ısının oranına bağlı olarak Denklem (2) 'ye göre hesaplanmaktadır:

$W_{e}=W_{\exp } \frac{H_{e x p}^{d}}{H_{T N T}^{d}}(2)$

Burada $\mathrm{W}_{\mathrm{e}}$ TNT eş değer ağırlığını [kg], $\mathrm{W}_{\text {exp }}$ gerçek patlayıcının ağırlığını [kg], $\mathrm{H}_{\text {exp }}^{\mathrm{d}}$ gerçek patlayıcının patlama 1 Sisını [MJ / kg], ve $\mathrm{H}^{\mathrm{d}}{ }_{\text {TNT }}$ TNT'nin patlama 1 sisını ifade etmektedir [MJ / kg].

En yaygın patlama ölçeklendirme yasalarından biri Hopkinson-Cranz tarafından geliştirilendir. Hopkinson-Cranz yasasına göre, Denklem (3)'te tarif edildiği gibi bir ölçeklendirilmiş mesafe hesaplanmaktadır:

$\mathrm{Z}=\frac{R}{\sqrt[3]{W_{e}}}(3)$

Burada R, patlama kaynağından hedef noktasına olan mesafedir. 


\subsection{En Yüksek Patlama Basınç Yükü}

Patlama basıncı ile ilgili ilk çalışmalar 1950'li yıllarda yapılmıştır. Brode (1955) patlamanın büyüklüğüne bağlı bir yaklaşım geliştirmiştir[5]. Kinney(1985), kimyasal tip patlamalara dayanan bir formülasyon geliştirmiştir[9]. Mills (1987), yakın tarihte maksimum basıncın " $\mathrm{kPa}$ " cinsinden ifade edildiği ve ölçeklendirilmiş mesafenin kullanıldığı bir formülasyon geliştirmiştir(Denklem $4)$.

$\mathrm{P}_{\mathrm{So}}=\frac{1772}{Z^{3}}-\frac{114}{Z^{2}}+\frac{108}{Z}$

\section{Sayısal Çalışma}

Mevcut modellemesi yapılan bina 3 katlı olup x yönünde 5, y yönünde 3 açıklıklı bir okul binasıdır. Yapı simetrik düzenli olup betonarme çerçeve taşıyıı sisteme sahiptir. Patlama yükü hedefe 10m mesafeden binanın doğu-batı doğrultusunda binanın ön yüzüne isabet edecek şekilde konumlandırılmıştır (Şekil 1).

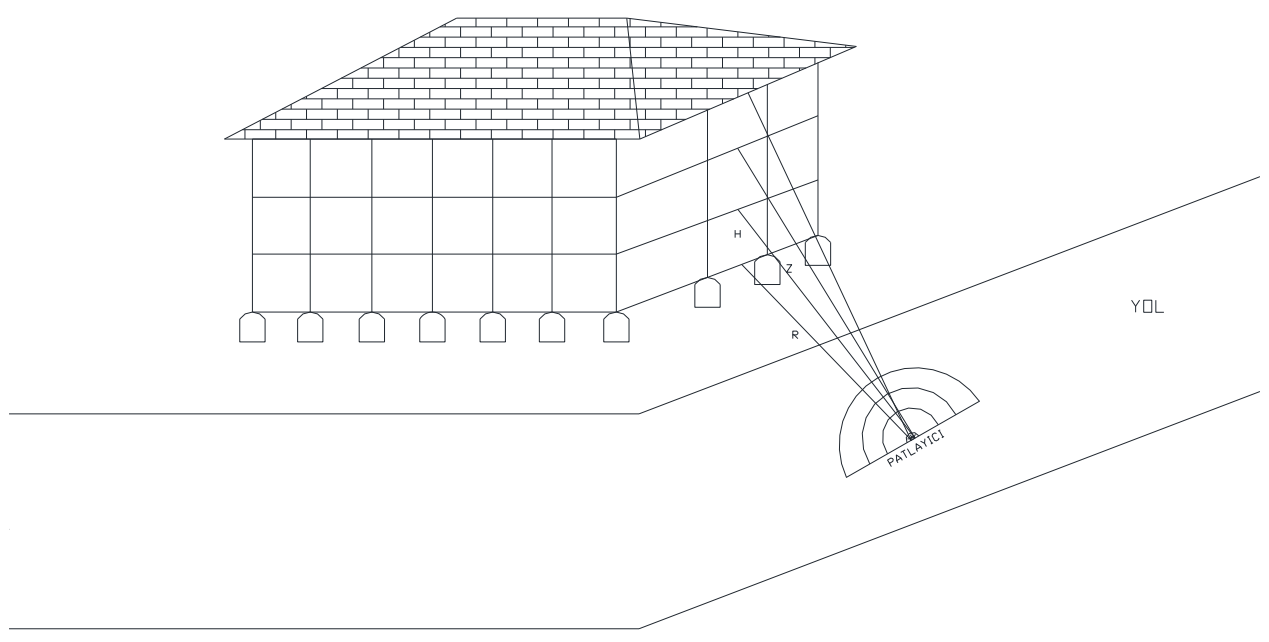

Şekil 1.Patlama etkisi altında sismik yalıtımlı bina modeli

Mevcut binaya ait bilgiler Tablo 1'de verilmiş olup binada C25 betonu ve S420 çeliği kullanılmıştır. Beton ve çelik malzeme modelleri "Türkiye Bina Deprem Yönetmeliği, 2018” de tanımlanan gerilme-şekil değiştirme bağıntıları kullanılarak elde edilmiştir.

Tablo 1. Bina Bilgileri

\begin{tabular}{ll}
\hline Beton sınıf: & C25 \\
\hline Donatı sınıfı: & S420 \\
\hline Kolon Boyutu: & $350 / 600$ ve $600 / 350$ \\
\hline
\end{tabular}




\begin{tabular}{ll}
\hline Kolon donatıları: & $16 \phi 16$ \\
\hline Kiriş Boyutu: & $200 / 600$ ve $300 / 600$ \\
\hline Kiriş Donatıları: & $2 \phi 14+2 \phi 16$ ve $2 \phi 14+3 \phi 16$ \\
\hline
\end{tabular}

Sismik yalıtımlı bina tabanında kulanılan kurşun çekirdekli kauçuk sönümleyicilerin yatay ve düşey yük kapasiteleri Tablo 2'de verilmiştir:

Tablo 2. Kurşun çekirdekli kauçuk esaslı sismik sönümleyici özellikleri

\begin{tabular}{ll}
\hline Parametreler & \\
\hline Düşey yönde yalıtım birimi lineer rijitliği $[\mathbf{k N} / \mathbf{m}]=\mathbf{K}_{\mathbf{v}}$ & 5017389,3 \\
\hline Yatay yönde yalıtım birimi nonlineer rijitliği $[\mathbf{k N} / \mathbf{m}]=\mathbf{K}_{\mathbf{H}}$ & 6261,62 \\
\hline Yatay yönde yalıtım birimi akma dayanımı $[\mathbf{k N}]=\mathbf{F}_{\mathbf{y}}$ & 1308,87 \\
\hline Yatay yönde yalıtım birimi akma sonrası rijitliğin akma öncesi rijitliğe oranı $=\mathbf{K}_{\mathbf{d}} / \mathbf{K}_{\mathbf{u}}$ & 0,1 \\
\hline
\end{tabular}

Mevcut yapıya yapılan yükleme Zaman Tanım Alanında Doğrusal Olmayan Analiz yöntemleriyle gerçekleştirilmiş olup; yüklemeler, birim alandan gelen yük etkileri hesaplanarak düğüm noktalarına etki ettirilmiştir. Patlayıcı malzeme özellikleri Tablo 3 'te verilmiştir:

Tablo 3. Patlayıcı Özellikleri

\begin{tabular}{ccc}
\hline $\mathbf{W}_{\text {exp }}[\mathbf{k g}]$ & $\mathbf{H}_{\text {exp }}[\mathbf{M J} / \mathbf{k g}]$ & $\mathbf{H}_{\text {TNT }}[\mathbf{M J} / \mathbf{k g}]$ \\
\hline 250 & 5,86 & 4,55 \\
\hline
\end{tabular}

Maksimum patlama yükü hesabında Mills' in geliştirdiği formülasyon kullanılmış olup Friedlander'in geliştirdiği patlama basınç yükü formülasyonuna göre patlama dalgası profili elde edilmiştir(Şekil 2).

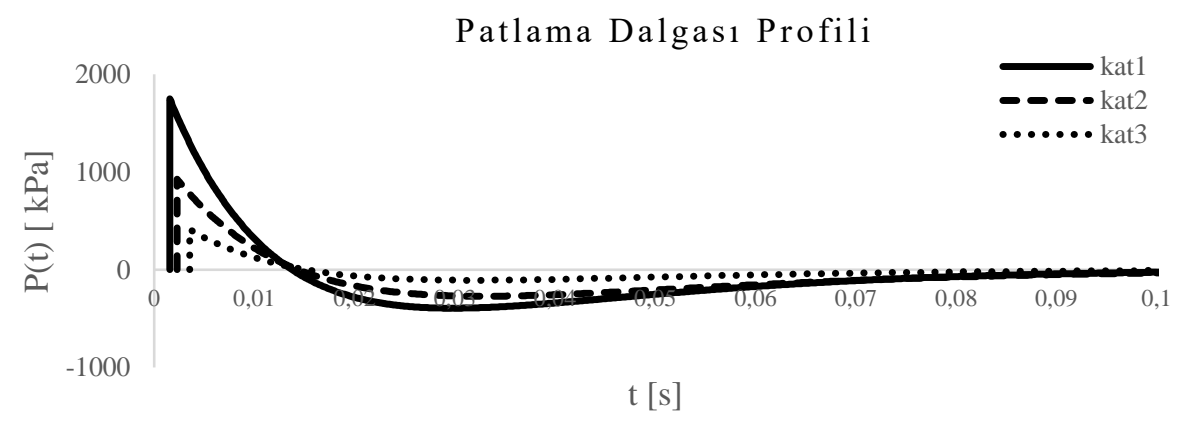

Şekil 2. $250 \mathrm{~kg} \mathrm{C4}$ tipi patlayıcıya ait patlama dalgası profili

Patlama olayı sonucunda binanın performansı "Türkiye Bina Deprem Yönetmeliği, 2018”e göre hesaplanan birim şekil değiştirme sınırlarına göre değerlendirilmiştir (Tablo 4). 
Tablo 4. Birim şekil değiştirme sınırları

\begin{tabular}{ll}
\hline Beton Birim Şekil Değiştime Oranları & Çelik Birim Şekil Değiştirme Oranları \\
\hline$\varepsilon_{c}^{[\mathrm{GO}]} \leq 0,018$ & $\boldsymbol{\varepsilon}_{s}{ }^{[\mathbf{G O}]} \leq 0,072$ \\
\hline$\varepsilon_{c}[\mathrm{KH}] \leq 0,0135$ & $\boldsymbol{\varepsilon}_{s}{ }^{[\mathrm{KH}]} \leq 0,054$ \\
\hline$\varepsilon_{\mathrm{c}}{ }^{[\mathrm{SH}]} \leq 0,0025$ & $\boldsymbol{\varepsilon}_{s}{ }^{[\mathrm{SH}]} \leq 0,0075$ \\
\hline
\end{tabular}

\section{Sonuçlar}

Patlama analizi sonucunda sismik yalıtımsız ve sismik yalıtımlı binalar değerlendirildiğinde $10 \mathrm{~m}$ mesafede yapılan yüklemede yalıtımlı binada oluşan plastik mafsal miktarının daha az olduğu gözlenmiştir.

Yalıtımlı ve yalıtımsız binalara ait doğal titreşim mod şekilleri Şekil 3'te verilmiştir. Patlama yüklemesi sonucunda mod şekilleri incelendiğinde sismik yalıtımlı binada 1 . modun baskın olduğu görülürken sismik yalıtımsız binada 2. modun baskın olduğu görülmüştür (Şekil 4).
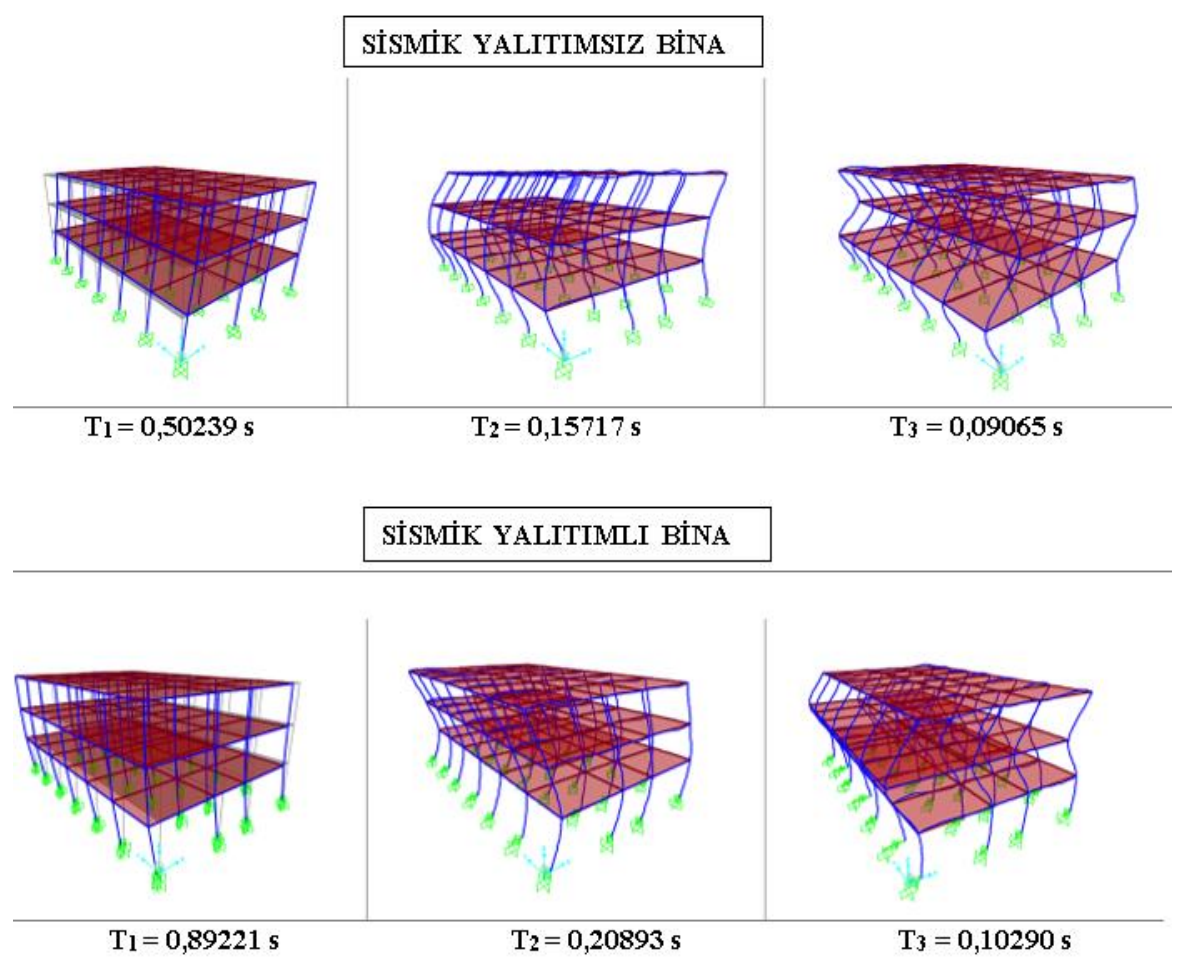

Şekil 3. Sismik yalıtımlı ve yalıtımsız bina modelleri ve plastik mafsal oluşumları 

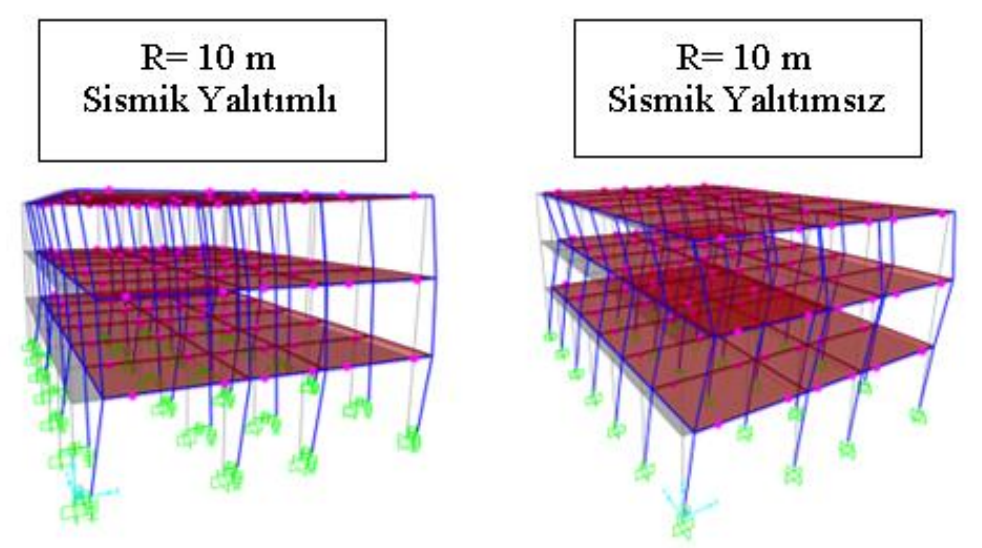

Şekil 4. Sismik yalıtımlı ve yalıtımsız bina modelleri ve plastik mafsal oluşumları

Tasarlanan yalıtım biriminin patlama yükü analizi sonucunda zamana bağlı yatay yer değiştirmeleri Şekil 5'te verilmiştir. Patlama yükü analizi sonucunda taban yalıtımlı binada oluşan taban kesme kuvvetleri (Şekil 6) ve moment etkileri azalmıştır (Tablo 5).

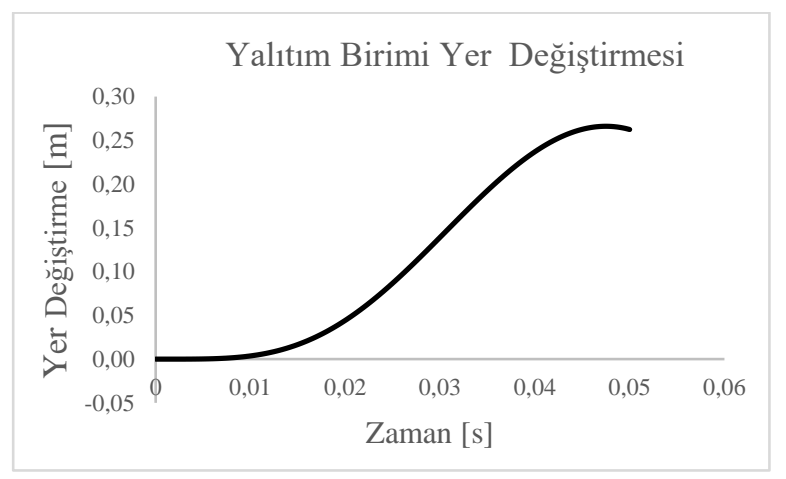

Şekil 5. Yalıtım birimi yatay yer değiştirmesi

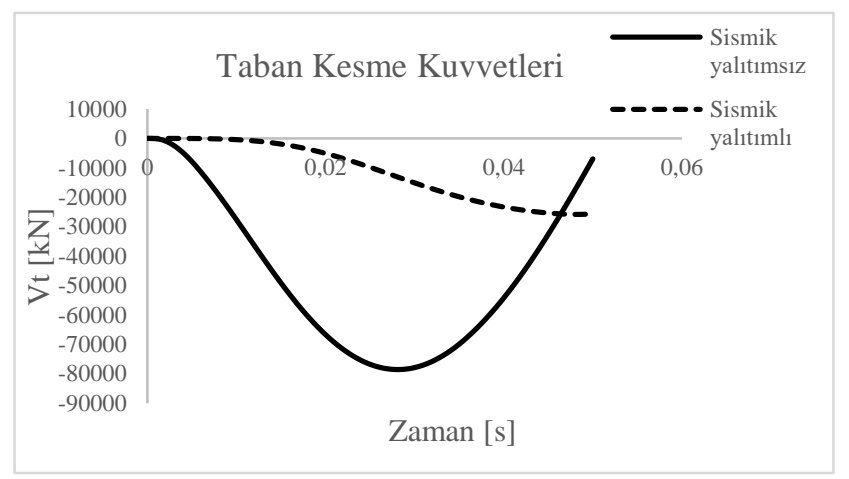

Şekil 6. Taban kesme kuvvetleri

Tablo 5. Kolonlarda oluşan maksimum moment değerleri [kN.m]

\begin{tabular}{ccc}
\hline & Sismik Yalıtımsız & Sismik Yalıtımlı \\
\hline Kat1 & 1941,40 & 353,60 \\
\hline Kat2 & 4600,53 & 937,19 \\
\hline Kat3 & 4340,65 & 1382,55 \\
\hline
\end{tabular}


Yapıda oluşan yer değişimleri katlara göre değerlendirildiğinde yalıtımlı binada yalıtımsız binaya oranla daha küresel bir davranış gerçekleşmiştir (Şekil 7).
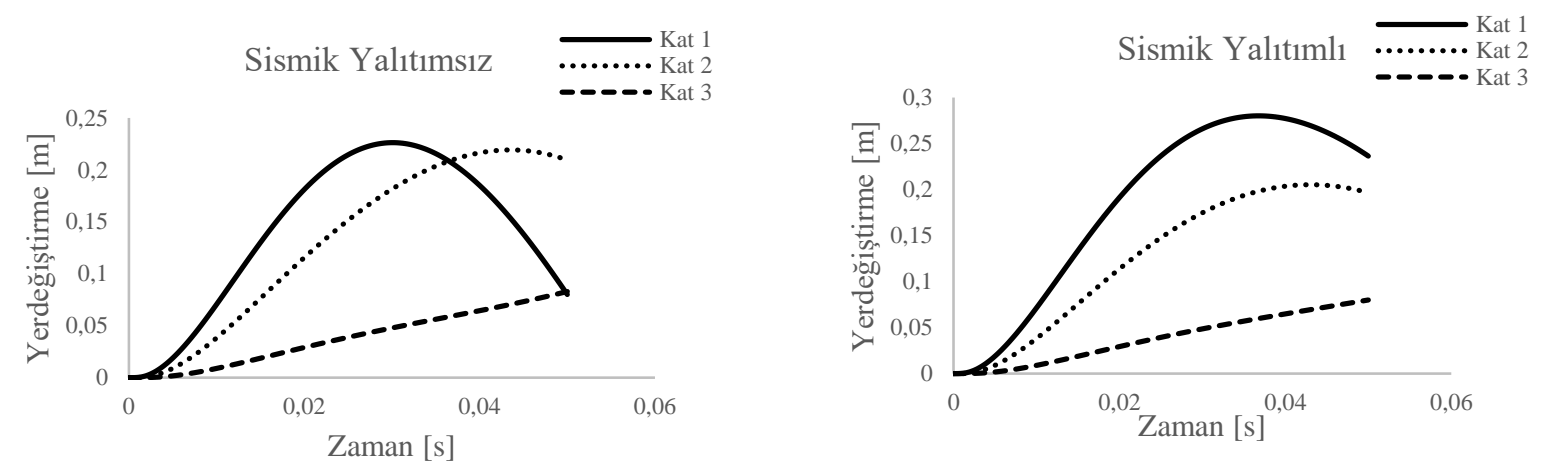

Şekil 7. Maksimum toplam kat yer değiştirmeleri

Göreli kat ötelemeleri oranları; 2018 Türkiye Bina Deprem Yönetmeliği’ne göre sismik yalıtımlı binada 0,0157, sismik yalıtımsız binada ise 0,0927 oranında hesaplanmıştır (Tablo 6).

Tablo 6. Göreli kat ötelemeleri kontrolü

\begin{tabular}{|c|c|c|c|c|}
\hline Sismik Yalıtımsız Bina & $\delta_{\mathrm{i} \max }[\mathrm{m}]$ & $\lambda$ & $h_{i}[\mathbf{m}]$ & $\lambda\left(\delta \operatorname{imax} / h_{i}\right) \leq 0,008 \kappa$ \\
\hline & 0,820 & 0,44 & 3,80 & Sağlamadi \\
\hline \multirow[t]{2}{*}{ Sismik Yalıtımlı Bina } & $\delta_{i \max }[\mathrm{m}]$ & $\lambda$ & $h_{i}[\mathrm{~m}]$ & $\lambda\left(\delta \operatorname{imax} / h_{i}\right) \leq \mathbf{0 , 0 1 h _ { i }}$ \\
\hline & 0,136 & 0,43 & 3,80 & Sağladı \\
\hline
\end{tabular}

Yapılan analizler sonucunda sadece kirişlerde plastik mafsal oluşumu gözlenmiştir.2018 Türkiye Bina Deprem Yönetmeliği'ne göre Belirgin Hasar bölgesine kirişlerin en fazla \%20 si İleri hasar Bölgesine kirişlerin en fazla \% 35 i ve Göçme bölgesine kirişlerin en fazla \%20 si geçebilmektedir. Şekil 8'de hasar sınırlarını aşan kirişlerin oranı verilmiştir.
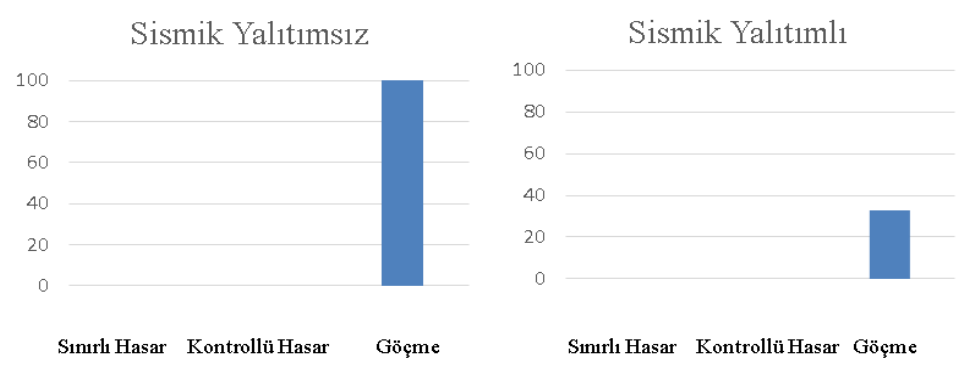

Şekil 8. Hasar sınırlarını aşan kiriş oranları

Yapılan analiz sonucunda yalıtımsız binada kirişlerin \%100' ü göçme bölgesinde iken yalıtımlı binada ise kirişlerin \%32,6 s1 göçme bölgesine geçmiştir. 


\section{Tartışma}

Patlama ve sismik yüklerinin verdiği hasar bakımından sismik yükleme küresel patlama yükleri lokal hasara sebep olduğundan karşılaştırılması mümkün olmamaktadır. Ancak sismik yalıtım araçlarının kullanımının sismik ve patlama yüklerine maruz binalar için optimum bir fayda sağlayacağı düşünülmektedir. Taban yalıtımı haricinde aktif ve pasif sönümleyicilerinin de etkileri araştırılmalıdır.Sismik yüklere karşı korunmuş bina patlamaya karşı korunmuş olmamaktadır.Patlama yükleri verdiği lokal hasarın yanında yangına yüksek basınç etkisiyle taşıyıcı olmayan elemanların tahribi ile can ve mal kayıplarına yol açmaktadır. Bu nedenle can güvenliğinin sağlanmasında taşıyıcı sistem haricinde taşıyıcı olmayan elemanların verebileceği zararlar da gözönünde bulundurulmalıdır. Patlama olayına maruz kalma ihtimali bulunan binalar daha korunaklı bölgelere inşa edilmeli ve gerekirse bina etrafi korunaklı duvarlarla çevrelenmelidir. Tanımlanacak yüklerin daha gerçekçi tanımlanabilmesi için gerçek ölçümler yapılmalıdır. Bu çalışma sadece tek bir patlayıcı tipi için değerlendirlmiş olup farklı tip patlayıcılara göre farklı mesafelere göre değerlendirmelerin yapılması ve binanın dayanımının artırılmasına yönelik alternatif malzeme modellerinin geliştirilmesi ve kullanılması güvenliğin sağlanması bakımından etkili olacaktır. 


\section{Kaynaklar}

[1] Özçelik, N. PKK ve Bombalı Araç Saldırıları.SETA.2016, Ekim.

[2] Zhang, R., \& Phillips, B. M. Numerical study on the benefits of base isolation for blast loading. In 6th international conference on advances in experimental structural engineering, 11th international on advance smart materials and smart structures technology workshop, United States, 2015.

[3] Chopra, A.K. Yapı Dinamiği Teori ve Deprem Mühendisliği Uygulamaları.4.bask1.Ankara; Palme, 2015

[4] Code, U. B. (1997). UBC-97. In Structural engineering design provisions. International conference of building officials, Whittier, California.

[5] Brode H. L., (1955) "Numerical solution of spherical blast waves", Journal of Applied Physics, American Institute of Physics, New York.

[6] Henrych, J., \& Major, R. (1979). The dynamics of explosion and its use (Vol. 569). Amsterdam: Elsevier.

[7] Baker, W. E., Cox, P.S., Kulesz, J.J., and Stehlow, R.A. (1983). Explosion hazards and evaluation, Elsevier Scientific, Amsterdam, Netherlands.

[8] Kingery, C. N., \& Bulmash, G. (1984). Air blast parameters from TNT spherical air burst and hemispherical surface burst. US Army Armament and Development Center, Ballistic Research Laboratory.

[9] Kinney, G. F., \& Graham, K. J. (2013). Explosive shocks in air. Springer Science \& Business Media.

[10] ASCE. (2010). "Design of blast resistant buildings in petrochemical facilities." Petrochemical Committee, Task Committee on Blast Resistant Design, ASCE, New York.

[11] Mays G.C., Smith P.D., (2001) "Blast effects on buildings - Design of buildings to optimize resistance to blast loading", Tomas Telford.

[12] Bulson P. S., (1997) "Explosive Loading of Engineering Structures", Chapman and Hall. [13] Mills C. A. (1987) "The design of concrete structures to resist explosions and weapon effects". Proceedings of the 1st Int. Conference on concrete for hazard protections, Edinburgh, UK. 